\title{
A PEDAGOGIA DA UNIVERSIDADE FEDERAL DE MATO GROSSO DO SUL CAMPUS DE NAVIRAÍ/MS: A CRECHE NA FORMAÇÃO INICIAL DE PROFESSORES
}

\author{
Klinger Teodoro Ciríaco, Giseli Tavares de Souza Rodrigues
}

Universidade Federal de Mato Grosso do Sul - UFMS, Curso de Pedagogia, Câmpus de Naviraí, Naviraí, MS. E-mail: klingerufms@hotmail.com

\section{RESUMO}

O objetivo dessa pesquisa foi investigar as características e contribuições da formação inicial de professores para atuar na Educação Infantil de (0 a 3 anos). Esse trabalho refere-se a uma pesquisa de Trabalho de Conclusão de Curso (TCC), na qual aqui, será apresentada apenas a primeira parte do estudo. Assim, aponhamos nos pressupostos da pesquisa qualitativa, mais especificamente, com vistas para a análise documental sobre as especificidades da creche abordadas na grade curricular do curso de Pedagogia da Universidade Federal de Mato Grosso do Sul, Campus de Naviraí/MS, (UFMS/CPNV). Na análise dos dados, é possível identificar que as discussões sobre a infância e a creche no currículo do curso investigado, são ainda poucas e que muitas das disciplinas específicas sobre a área, pertence ao quadro de disciplinas optativas. Desse modo, podemos dizer que, seria fundamental, a criação de um movimento na formação inicial, por uma Pedagogia mais específica para atuação na Infância, pois a experiência de atuação e estudante do curso, tem nos apresentado o quanto os conteúdos sobre a creche e as discussões sobre o profissional da Educação Infantil, não são o centro de partida para a formação inicial, mas sim, é algo pensado em segunda ordem.

Palavras-chave: Curso de Pedagogia; Educação Infantil (0-3 anos); Formação de Professores.

\section{THE PEDAGOGY OF MATO GROSSO FEDERAL UNIVERSITY CAMPUS OF SOUTH Ashland / MS: A NURSERY IN THE INITIAL TRAINING OF TEACHERS}

\begin{abstract}
The objective of this research was to investigate the characteristics and contributions of initial teacher training to work in Early Childhood Education (0-3 years). This paper refers to a research work Course Conclusion (TCC), which here will be presented only the first part of the study. So aponhamos the precepts of qualitative research, more specifically, in order to document analysis on the specifics of the nursery addressed in the curriculum of Education, Federal University of Mato Grosso do Sul, Campus Ashland / MS, (UFMS / CPNv). In data analysis, you can identify that discussions about childhood and kindergarten curriculum in the investigated course, are still few and that many of the specific disciplines of the area belongs to the elective courses above. Thus, we can say that would be fundamental, creating a movement in the initial training, for a more specific pedagogy to operate in Childhood, because the work experience and student travel, has shown us how much the contents of the nursery and discussions on the professional from kindergarten, are not the starting center for initial training, but it is something thought of second order.
\end{abstract}

Keywords: Education Course; Early Childhood Education (0-3 years); Teacher Education. 


\section{INTRODUÇÃO}

$\mathrm{O}$ interesse em pesquisar pelo tema surgiu por meio de 2 anos de observações durante estágio remunerado em uma das creches municipais da cidade de Naviraí do Estado de Mato Grosso do Sul (MS). Foram observados as atitudes e perfis das professoras, momentos estes em que percebemos que elas faziam um bom trabalho, contudo, foi possível notar que era possível fazer algo ainda melhor, que viesse realmente ao encontro das especificidades do desenvolvimento integral da criança. Sendo assim, é possível afirmar que a falta dessa especificidade do trabalho das professoras observadas, pode estar relacionada com a formação inicial que obtiveram que nem sempre dá condições, teórico-metodológicas para a atuação no espaço da creche.

Dessa forma, pensando no trabalho dessas profissionais foi feito uma comparação, com o curso de Pedagogia da Universidade Federal de Mato Grosso do Sul, Câmpus de Naviraí/MS, (UFMS/CPNV) e foi constatado que o mesmo parece não oportunizar discussões sobre o trabalho docente na creche ao longo da formação inicial e, desse modo, acaba sendo quase inexistentes essas discussões durante os quatro anos do curso. É desse lugar que falamos, dessa inquietude que nos fez interessar por tal temática: a formação de professores de creche.

Assim, essa pesquisa refere-se a um estudo desenvolvido em nível de Trabalho de Conclusão de Curso (TCC), e nesse trabalho, será abordada a primeira parte da pesquisa, na qual teve por objetivo, apresentar dados referentes ao lugar destinado às discussões sobre a creche (0 a 3 anos) no currículo do curso de Pedagogia da (UFMS/CPNV).

Segundo a Lei de Diretrizes e Bases da Educação Nacional (LDB), Lei 9394/96 em seu art. 29, a Educação Infantil tem o objetivo de contribuir com o desenvolvimento integral da criança até 5 anos de idade estabelecido pela Lei (11.274/2006), que amplia o Ensino Fundamental para nove anos, em seus aspectos físico, psicológico, intelectual, motor e social complementando a ação da família e da sociedade.

No entanto, para que isso ocorra, é preciso contar também com profissionais com formação específica, pois lidar com crianças e, principalmente de 0 a 3 anos, requer aspectos e atitudes específicas, porque nessa fase a criança depende muito das intervenções e estimulações do adulto para que possa se desenvolver de forma plena, atendendo assim, os pressupostos da (LDB).

Entretanto, é importante destacar que a criança precisa ser o ponto de partida 
para as atividades pedagógicas previstas no ambiente da creche e, para isso, se o professor não tiver uma formação específica, dificilmente ele conseguirá contribuir para o aprendizado e desenvolvimento infantil.

Sendo assim, vale dizer que é necessário que o profissional tenha uma formação centrada na Pedagogia da Educação Infantil para melhor atender as especificidades da criança de 0 a 3 anos. Segundo Kishimoto (2005), a Pedagogia da Infância poderia trabalhar com concepções sobre a criança e Educação Infantil, no que se refere às práticas integradas que forneçam compreensão da criança como ser ativo que possui identidade e cultura abordando áreas disciplinares conduzindo o conhecimento.

"É a Pedagogia da Educação Infantil, que deve servir de indicador para a construção da identidade da professora de Educação Infantil cuja meta é constituída pela educação e o cuidado das crianças pequenas" (CERISARA, 2002, p. 101).

Dessa forma, Cerisara (2002) declara que todo profissional precisa construir sua identidade e perfil, isto é, o profissional precisa se encontrar, se identificar com a profissão, principalmente, quando se refere ao trabalho com crianças pequenas. Para tanto, requer uma formação que contemple os pressupostos da Pedagogia da infância, ou seja, precisa prever, em sua grade curricular, disciplinas que tenham como componentes centrais discussões teórico-metodológicas sobre como se realiza o trabalho na creche. Contudo, o que é mais evidente, no contexto dos cursos de formação inicial de professores, no caso da Pedagogia, as discussões sobre pré-escola tendo ênfase no papel da escola e nos processos de escolarização da criança.

Desse modo, uma questão central tem nos acompanhado durante o processo investigativo de nossa pesquisa, a saber: $A$ grade curricular do curso de Pedagogia da (UFMS/CPNV) prevê conteúdos programáticos que forneçam subsídios teórico-metodológicos para atuação do professor na creche 0 a 3 anos?

Estima-se que os frutos desse trabalho contribuam para a compreensão das especificidades do trabalho pedagógico na Educação Infantil, bem como para a docência na infância e também que os cursos de formação inicial a partir desse, se necessário, possam passar por possíveis reformulações para que venham realmente formar profissionais que tenham competências suficientes e específicas para trabalhar com a criança pequena.

\section{Educação infantil: Aspectos relevantes que} não podem faltar na formação inicial para atuar na creche

Segundo o Referencial Curricular Nacional para Educação Infantil (BRASIL, 
1998) o profissional que antes atuava com as crianças pequenas era conhecido como berçarista, babás, pajem, monitor, entre outros. Essas pessoas não tinham uma qualificação suficiente nem perfil adequado para atuar na área, mas ao longo dos anos tal situação foi se modificando, com o surgimento de políticas que reconheceram a Educação Infantil como a primeira etapa da Educação Básica.

Desse modo, surgiram leis e diretrizes curriculares para a formação de professores no Brasil que, no caso da Educação Infantil, já ressaltam a relevância de ser ter um profissional formado em nível superior com habilitação específica na área. Nessa perspectiva, a LDB 9394/96, em seu art.61 e 62, afirma que os profissionais da Educação Básica que estão em efetiva função e têm sido formados em cursos com reconhecimento, são os professores capacitados em Nível Médio ou Superior para atuar na Educação Infantil e no Ensino Fundamental. São, portano docentes que tenham diploma de Pedagogia, com habilidades em administração, planejamento, supervisão, inspeção e orientação educacional, bem como habilitação de mestrado ou doutorado com as mesmas finalidades.

Dessa maneira, a formação de professores para atuar na Educação Infantil deverá ser feita em Nível Superior, no curso de licenciatura, em Universidades e Instituições Superiores de Educação (BRASIL, 2010). Micarello (2005) argumenta ser importante, durante a formação inicial, os professores serem bem preparados para atuar na Educação Infantil, pois essa fase é muito importante na vida da criança. É o momento em que a infância está em desenvolvimento e o professor precisa estar preparado para contribuir com essa etapa.

Cerisara (2002, p.100) comenta que, “(...) professoras de crianças pequenas em instituição de Educação Infantil precisam definir sua prática profissional visando o exercício de uma profissão docente, que tem sua especificidade definida pela pedagogia de Educação Infantil".

Desse modo, Kramer (2005), menciona que a Educação Infantil tem a função de priorizar os conhecimentos que as crianças têm e assegurar novas aprendizagens, mas para isso é viável que professor reconheça as características e finalidades da infância respeitando a capacidade de criação e imaginação da criança.

Nesse ensejo, é fundamental que esse profissional compreenda a criança como um ser histórico, social e cultural. Também para que ele realize uma boa ação pedagógica é necessário refletir sobre o seu trabalho, e ter estudo crítico sobre teorias. Dessa forma, compreenderá melhor a prática em que atua. 
Santos e Leite (2012), contribuem com a discussão quando enfatizam que:

[...] se faz necessária a formação de professores que estejam dispostos a refletir sobre sua prática pedagógica, a fim de torná-la um instrumento que permita a sua reflexão crítica, visando adequar sua prática de acordo com o contexto em que o sujeito está envolvido, bem como aprimorar as metodologias utilizadas em sua prática pedagógica. (2012, p. 675).

Dessa forma, Kramer (2005, p. 224 225) evidencia que:

Para ser professor, mais do que gostar de ensinar, é preciso gostar de aprender, o que implica em compreender que a formação científica, cultural e política não para. Mesmo quem não pretende ser pesquisador precisa saber como que a pesquisa é produzida, estar atento aos estudos de vários campos, valorizar a teoria, o conhecimento científico, as respostas encontradas para as velhas perguntas e as novas que nascem com elas.

Por esse viés, podemos afirmar que é muito importante que o professor esteja sempre buscando conhecimentos novos e que crie oportunidades em que ele venha não só ensinar, mas também aprender com as pessoas que convive no seu dia a dia, principalmente com as do ambiente de trabalho e com as crianças onde há o contato social. Sobre esse prisma, "A Educação Infantil hoje precisa ser pautada em conhecimentos científicos básicos para a formação do professor e os conhecimentos necessários para o trabalho com a criança pequena" (ARAÚJO, 2005, p. 58). Tal formação pressupõe, sem dúvidas, uma especificidade durante o curso inicial.

Santos e Leite (2012, p. 671) comenta que "Assim sendo, todos os profissionais envolvidos com a Educação Infantil necessitam assumir o compromisso de atender todas as necessidades das crianças, bem como respeitar suas diferenças e especificidades, a fim de proporcionar uma educação de qualidade". Para que esse pressuposto ocorra é, recomendável, que o futuro professor adquira, durante sua formação inicial, um repertório de conhecimentos teórico-metodológicos centrado nas especificidades da Pedagogia para a Infância, o que nem sempre ocorre, pois no caso do profissional da Educação Infantil temos, como aponta Cerisara (2002), um grande desafio: a falta dessa especificidade.

Falar em professora de educação infantil é diferente de falar em professora das séries iniciais e isso precisa ser explicitado para que as especificidades do trabalho das professores de crianças de 0 a 6 anos em instituições coletivas públicas de educação e cuidado sejam garantidas. (p. 334).

Nessa perspectiva, acredita-se que o profissional que atua com a criança de 0 a 3 
anos precisa adquirir um perfil e identidade adequada reconhecendo o valor da especificidade da Educação Infantil e que seja realmente um profissional com conhecimentos específicos na área, que viva em constante reflexão sobre a sua prática e também que esteja sempre se atualizando, em formação permanente, para melhor atender e auxiliar nas necessidades da criança. (SANTOS; LEITE, 2012).

\section{ABORDAGEM METODOLÓGICA}

A abordagem metodológica utilizada foi à qualitativa de caráter analítico, o que significa dizer que nos aproximamos do objeto de estudo com vistas à caracterização dos elementos pertinentes para atingir o objetivo proposto.

Desse modo, a pesquisa qualitativa em educação vem ganhando espaço significativo nos estudos e pesquisas nos últimos anos. Esse fato deve-se a grande proximidade entre o pesquisador e a situação investigada justamente porque essa metodologia de pesquisa permite a imersão no cenário natural, ou seja, o pesquisador tem uma relação de proximidade com o contexto pesquisado $o$ que lhe permite captar informações mais detalhadas sobre o processo, bem como para que discuta qualitativamente os dados coletados.

Bogdan e Biklen (2004) consideram que:
A investigação qualitativa é descritiva. Os dados recolhidos são em sua forma de palavras ou imagens não de números. Os resultados escritos da investigação contem citações feitas com base nos dados para ilustrar ou substanciar a apresentação. Os dados incluem transcrições de entrevistas, notas de campo, fotografias, vídeos, documentos pessoais, memorandos e outros registros oficiais. (p. 48).

Nessa perspectiva, é que essa pesquisa se enquadra e os dados que aqui serão apresentados, referem-se à análise documental que realizamos na grade curricular do curso de Pedagogia da (UFMS/CPNV). Tal análise é relevante porque, procuramos identificar qual o espaço/lugar destinado à Educação Infantil, mais especificamente a creche, no currículo do curso.

Utilizamos a análise documental como forma de coletar os dados que subsidiam pedagogicamente o trabalho com as práticas de cuidado e educação durante a formação inicial dos professores da (UFMS/CPNV). O foco, nesse processo, foi encontrar elementos que nos permitissem caracterizar os aspectos ligados à infância, a criança, as práticas de cuidado e educação em instituições de Educação Infantil de (0 a 3 anos). "Os documentos constituem uma fonte poderosa de onde podem ser retiradas evidências que fundamentam afirmações e 
declarações do pesquisador". (LUDKE e ANDRÉ, 1995, p. 39).

O lugar da creche na grade curricular do curso de Pedagogia da Universidade Federal de Mato Grosso do Sul campus de Naviraí/MS - UFMS/CPNV

Ao ser entendida como um campo pedagógico, a Educação Infantil precisa preencher um espaço significativo em discussões teórico-metodológicas durante a formação inicial de professores. É preciso que - aluno da graduação compreenda as especificidades da docência na infância. Nesse sentido, temos nos indagado, ao longo da pesquisa, qual seria, então, o lugar destinado às práticas/teorias sobre creche na formação inicial?

Com relação a essa questão, o Projeto Político Pedagógico (PPP) do curso, afirma que $o$ acadêmico egresso precisa ter habilidade para entender, cuidar e educar crianças de 0 a 5 anos de maneira que contribua para o seu desenvolvimento nas dimensões física, psicológica, intelectual e social. Essa visão se assemelha e complementa o art. 29 da LDB. (BRASIL, 1996).

Nessa perspectiva, para que o egresso saia da Instituição de Ensino Superior com alguns conhecimentos básicos das especificidades do trabalho pedagógico com crianças pequenas, é necessário que o curso tenha dado a oportunidade para que o acadêmico compreenda o que é ser um professor de Educação Infantil, bem como reconheça que a prática pedagógica na infância se difere daquela exercida no Ensino Fundamental.

Conforme o objetivo proposto, organizamos 1 quadro das disciplinas que anunciam aspectos referente a Educação Infantil do curso ora analisado, conforme verificaremos abaixo: 
Quadro 01. Relação de disciplinas obrigatórias que anunciam aspectos ligados à Educação Infantil

\begin{tabular}{|c|c|c|c|}
\hline SEMESTRE & DISCIPLINAS & $\mathrm{CH}$ & $\begin{array}{l}\text { ASPECTOS LIGADOS À EDUCAÇÃO INFANTIL } \\
\text { CONFORME AS EMENTAS DAS DISCIPLINAS }\end{array}$ \\
\hline 10 & Psicologia da Educação & 85 & $\begin{array}{l}\text { Fases desenvolvimento infantil e implicações para a } \\
\text { prática docente. }\end{array}$ \\
\hline 20 & $\begin{array}{l}\text { Psicologia, Infância e } \\
\text { Educação }\end{array}$ & 85 & $\begin{array}{l}\text { Fases da aprendizagem da criança e implicações para } \\
\text { a prática docente. }\end{array}$ \\
\hline 3은 & $\begin{array}{l}\text { Fundamentos e } \\
\text { Metodologia do Ensino de } \\
\text { Ciências para Educação da } \\
\text { Infância. }\end{array}$ & 85 & $\begin{array}{l}\text { Conceito de ciência, ambiente, educação e } \\
\text { sociedade. Conteúdos específicos na educação } \\
\text { infantil. Ciências e os temas transversais. }\end{array}$ \\
\hline \multirow[t]{2}{*}{40} & $\begin{array}{l}\text { Fundamentos e } \\
\text { Metodologia do Ensino de } \\
\text { Geografia para a Educação } \\
\text { da infância. }\end{array}$ & 85 & $\begin{array}{l}\text { Estudo de objetivos e conteúdos ligados a Geografia } \\
\text { para a Educação Infantil. }\end{array}$ \\
\hline & Infância e Sociedade. & 68 & $\begin{array}{l}\text { O surgimento do sentimento de infância e ausência } \\
\text { do valor da criança, estudo da criança considerada } \\
\text { adulto em miniatura. }\end{array}$ \\
\hline 50 & $\begin{array}{l}\text { Estágio Obrigatório em } \\
\text { Educação Infantil I. }\end{array}$ & 102 & $\begin{array}{l}\text { Desenvolvimento de atividades para o } \\
\text { conhecimento, acompanhamento concreto em } \\
\text { instituições infantis, aplicado através da regência de } \\
\text { projetos voltados para a educação infantil de } 0 \text { a } 3 \\
\text { anos. }\end{array}$ \\
\hline \multirow[t]{2}{*}{$6 ㅇ$} & $\begin{array}{l}\text { Estágio Obrigatório em } \\
\text { Educação Infantil II. }\end{array}$ & 85 & $\begin{array}{l}\text { Desenvolvimento de atividades para a } \\
\text { aprendizagem, acompanhamento concreto em sala } \\
\text { de aula, aplicado através da regência sendo um } \\
\text { protejo voltado para a educação infantil de } 4 \text { a } 5 \\
\text { anos. }\end{array}$ \\
\hline & $\begin{array}{lr}\text { Fundamentos } & \text { e } \\
\text { Metodologia } & \text { da } \\
\text { Alfabetização, Língua } & \text { e } \\
\text { Letramento para } & \text { a } \\
\text { Educação da Infância. } & \\
\end{array}$ & 85 & $\begin{array}{l}\text { Concepção e metodologias de alfabetização e } \\
\text { letramento. A leitura e a escrita como práticas } \\
\text { sociais. Educação Infantil os primeiros registros por } \\
\text { meio dos materiais pedagógicos. }\end{array}$ \\
\hline \multirow[b]{2}{*}{ 7은 } & $\begin{array}{l}\text { Fundamentos } \\
\text { Metodologia do Ensino de } \\
\text { História para Educação da } \\
\text { Infância. }\end{array}$ & 85 & $\begin{array}{l}\text { Estudo de objetivos e do conteúdo programático de } \\
\text { história para Educação Infantil e a relação entre a as } \\
\text { demais áreas do conhecimento. }\end{array}$ \\
\hline & $\begin{array}{l}\text { Fundamentos e } \\
\text { Metodologia do Ensino de } \\
\text { Matemática para Educação } \\
\text { da Infância. }\end{array}$ & 85 & $\begin{array}{l}\text { Concepção de matemática. Processo de construção } \\
\text { do pensamento matemático e do conceito de } \\
\text { número, conteúdos específicos de matemática na } \\
\text { educação infantil. Trabalho com a Matemática na } \\
\text { Educação Infantil através das noções matemáticas } \\
\text { por meio de jogos e brincadeiras, o "lúdico". }\end{array}$ \\
\hline 80 & & & \\
\hline
\end{tabular}

Fonte: RODRIGUES, T. S. G. 2013.

Conforme observações realizadas enquanto acadêmica e professor formador do curso, é importante esclarecer que as disciplinas que fazem parte do quadro permanente da grade curricular sobre a
Educação Infantil, ou seja, as obrigatórias acabam, em sua essência, discutindo mais os aspectos de como essas áreas do conhecimento se apresentam no campo do Ensino Fundamental do que na Educação 
Infantil. Um fator que contribui de forma significativa para isso é a carga horária das disciplinas que, muitas vezes, não dá conta de oportunizar discussões mais sistemáticas da infância, formas e conteúdos para a docência na Educação Infantil.

Kishimoto contribui com essa discussão quando autora afirma que:

A Habilitação integrada por
Magistério de Educação
Infantil e Séries Iniciais do
Ensino Fundamental cria o
viés da multiplicação de
fundamentos e metodologias
de ensino, em campos
disciplinares de Matemática,
Ciências, Português, História,
Geografia, Educação Física e
Artes, o que gera um modelo
de curso que reproduz
práticas do ensino
Fundamental reitera a
antecipação da escolaridade e
o descuido com pressupostos
de qualidade como a
integração entre cuidado e a
educação. Os cursos com
amplo espectro de formação,
para a faixa etária de 0 a 10
anos, perdem especificidade,
não dando conta dos
conteúdos tanto da formação
do (a) professor (a) quanto da
criança, para uma faixa etária
tão ampla. (KISHIMoTO, 2005,
p.183-184, grifo nosso).

Ao observar o quadro das disciplinas obrigatórias, é possível afirmar que em cada semestre são oferecidas poucas disciplinas na área da Educação Infantil. Segundo Kishimoto (2005), isso ocorre pela grande abrangência da área de formação quando temos um curso que habilita o futuro professor para a
Educação Básica de forma mais global. Isso nos aponta que, no caso desse estudo, é preciso que se preze por um movimento de uma Pedagogia da Infância, ou pela realidade pesquisada, que a grade curricular passe, necessariamente, por reformulações com vistas às especificidades da creche $(0$ a 3 anos).

Dessa forma, o curso de Pedagogia (CPNV/UFMS), tem o objetivo de formar professores para atuarem com crianças pequenas, mas pode-se dizer que a partir da grade curricular, observou-se a ausência de disciplinas suficientes para a atuação docente em instituições de Educação Infantil.

Conforme o Projeto Político Pedagógico (PPP), os alunos que ingressaram no curso em 2009, cursaram 204 horas-aulas de disciplinas complementares optativas, sendo estas, aprovadas pelo Colegiado do Curso de Pedagogia da (UFMS/CPNV).

Já os acadêmicos que entraram a partir de 2010, passaram há cursar 136 horas-aulas de disciplinas optativas, tendo também aproveitamento aqueles alunos que veem de outras licenciaturas. Desse modo, para melhores compreensões das análises dos dados que serão apresentadas mais adiante, segue abaixo 1 quadro, que nos dá um panorama das disciplinas optativas ligadas à Educação Infantil oferecidas pela grade curricular. 
Quadro 02. Relação de disciplinas optativas da área de Educação Infantil

\begin{tabular}{|c|c|c|}
\hline DISPLINAS & $\mathrm{CH}$ & ASPECTOS LIGADOS À EDUCAÇÃO INFANTIL \\
\hline Filosofia para Crianças & 68 & $\begin{array}{l}\text { Reflexão filosófica e modelos pedagógicos. Diferentes } \\
\text { formas de ensino-aprendizagem sobre a Infância e } \\
\text { educação. }\end{array}$ \\
\hline $\begin{array}{l}\text { Fundamentos e Metodologia } \\
\text { da Educação Infantil I }\end{array}$ & 68 & $\begin{array}{l}\text { Subsídios legais, teóricos e práticos para a organização e } \\
\text { desenvolvimento do currículo e do trabalho com crianças } \\
\text { pequenas, tendo como objetivo o educar e cuidar das } \\
\text { instituições de educação infantil para a efetivação de um } \\
\text { atendimento de qualidade. }\end{array}$ \\
\hline $\begin{array}{l}\text { Fundamentos e Metodologia } \\
\text { da Educação Infantil II }\end{array}$ & 68 & $\begin{array}{l}\text { Essa disciplina segue a sequência dos conteúdos teóricos e } \\
\text { práticos para a organização e desenvolvimento do currículo } \\
\text { e do trabalho com crianças pequenas, tendo como objetivo } \\
\text { o educar e cuidar das instituições de educação infantil para } \\
\text { a efetivação de um atendimento de qualidade. }\end{array}$ \\
\hline Infância e Letramento I & 68 & $\begin{array}{l}\text { Concepções de infância e letramento. Infância, letramento } \\
\text { e questões sociais. }\end{array}$ \\
\hline Infância e Letramento II & 68 & $\begin{array}{l}\text { A língua materna e os processos de desenvolvimento } \\
\text { linguístico. Conteúdo de processos de desenvolvimento da } \\
\text { linguagem oral e escrita pela criança: aspectos sócio } \\
\text { históricos e pedagógicos. Infância e letramento. }\end{array}$ \\
\hline $\begin{array}{l}\text { Infância e o Pensamento } \\
\text { Matemático }\end{array}$ & 68 & $\begin{array}{l}\text { A elaboração da matemática e sua importância para } \\
\text { formação do pensamento matemático na criança. Escrita da } \\
\text { linguagem matemática nos aspectos sócio históricos e } \\
\text { psicológicos; relações entre escrita e leitura da linguagem } \\
\text { matemática. }\end{array}$ \\
\hline $\begin{array}{ll}\text { Infância, } & \text { Múltiplas } \\
\text { Linguagens e Mídia } & \end{array}$ & 68 & $\begin{array}{l}\text { Inicio do conceito de cibercultura. Teorias da aprendizagem } \\
\text { subjacentes às metodologias de ensino por computador. } \\
\text { Noções Básicas na área de informática e tecnologia. } \\
\text { Possibilidades de aplicação da tecnologia na educação. } \\
\text { Conhecimento de aplicativos referentes à educação. }\end{array}$ \\
\hline TOTAL & 476 & \\
\hline
\end{tabular}

Fonte: RODRIGUES, T. S. G. 2013.

A partir desse quadro, podemos notar

a existência de disciplinas sobre Educação

Infantil que, no nosso entender, todas elas

parecem ser componentes importantes e que

precisariam ser obrigatórias, principalmente

as 'Fundamentos e Metodologia da Educação

Infantil I', 'Fundamentos e Metodologia da

Educação Infantil II', bem como, 'Infância,

Múltiplas Linguagens e Mídia'. Tais

disciplinas são fundamentais para um perfil

de formação indicado para a docência em

turmas de creches e pré-escola.
Contudo, conforme verificamos, essas disciplinas são oferecidas como optativas o que evidencia a "fragilizada" formação de profissionais para atuarem nesse segmento da educação. Todas essas disciplinas apresentadas como optativas contribuiriam de maneira precisa na formação do professor de crianças pequenas, pois os conteúdos presentes nelas fazem parte dos aspectos e especificidades do processo de desenvolvimento infantil, bem como apresentam características do trabalho pedagógico deste profissional. 
Kishimoto (2005), em análise dos cursos de Pedagogia e seus impactos para a formação do professor de Educação Infantil no Brasil, salienta que: organização curricular adotada pelos cursos, até para propor um leque maior de ofertas, opção problemática, mas de interesse econômico, é a de um bloco de formação comum, seguido de pelo menos duas habilitações. A formação básica contempla de $58 \%$ a $70 \%$ da carga horária do curso, $10 \%$ de estágio e, as habilitações, de $10 \%$ a $16 \%$. Em algumas instituições, a estrutura curricular, inchada pelo conjunto de disciplinas de formação do pedagogo, prima pela falta de especificidade, com disciplinas de formação geral repetidas nos quarto semestres: outras apresentam uma sucessão de fatos lineares que se iniciam nos primórdios da civilização até os tempos atuais, sem foco na Pedagogia da Infância e nas construções/desconstruções de cada tempo. (2005, p. 182 , grifo nosso).

A realidade presente na grade curricular do curso que estamos analisando se assemelha às constatação de Kishimoto (2005). Os dados aqui problematizados sinalizam o quanto o curso em questão necessita rever a grade curricular no que se refere aos aspectos ligados à Educação Infantil, tendo uma atenção especial às discussões do trabalho na creche.
Os dados aqui apresentados nos permitem afirmar que nossa pesquisa confirma os dizeres de Santos e Haddad (2011) quando as autoras declaram que o campo de atuação das profissionais de creche vem sendo concebido por meio de uma formação que não se adquire conhecimentos específicos e habilidades para o exercício da função. Com isso, Santos e Haddad (2011, p. 9) ainda enfatizam que:

Em especial, a formação inicial para os profissionais que atuam na faixa etária de 0 a 3 anos, pois a formação para esses professores, demanda de reconhecimento nos currículos das universidades, sabendo que é visível a ausência de uma formação específica para as professoras de bebês, e mais é nas creches a presença maior de professores leigos, isso é de fato preocupante, quando estamos falando de professores que trabalham com bebês, essa fase tão importante da vida e que demanda de conhecimentos teóricos e práticos específicos.

Nessa mesma direção, Kiehn (2007) ao realizar uma pesquisa sobre as grades curriculares de alguns cursos de Pedagogia do Brasil, destaca que a formação de professores para Educação Infantil continua numa posição de segunda ordem, isso também ocorre na grade curricular do curso aqui apresentado, sendo a formação realizada por meio de pouco tempo com disciplinas e conteúdos restritos, pois a 
prioridade está na formação de professores para os anos iniciais do Ensino Fundamental. Segundo a autora:

A formação para educação
infantil está
representativamente
secundarizada e reflete, a
meu ver, o entendimento em
torno da formação de
profissionais para atuarem na
educação das crianças
pequenas e o lugar de
importância concedido à esse
nível de ensino. (KIEHN, 2007,
p. 70).

Cerisara (2004) alega que a Educação Infantil faz parte da Educação Básica e que o objetivo dessa área não é o ensino, mas sim a educação de crianças. Isso significa dizer que tal educação vai além da sistematização dos conteúdos, naturalmente observada no Ensino Fundamental, por que na idade de 0 a 3 anos, a criança está em pleno desenvolvimento de funções e conceitos que aprende e leva ao longo da vida.

Nesse sentido, a criança nessa faixa etária, adquire conhecimento a cada instante e em diferentes aspectos, pois é o momento em que constrói aprendizagens junto ao adulto (professor) e necessita de orientação em suas ações, tendo sempre em vista seu desenvolvimento pleno integrando, assim, o binômio cuidar e educar.

Contudo, acredita-se que para o professor obter conhecimentos sobre a atuação com crianças pequenas, compete à formação inicial oferecer subsídios necessários para que ele venha a ter clareza das especificidades da Educação Infantil de suas funções, bem como das características essenciais do trabalho pedagógico e conhecimentos teórico-metodológicos da área. Estamos aqui, em defesa de uma formação diferenciada e específica do professor de creche.

O que se deseja é que esse
campo disciplinar, embora
não seja uma tônica geral em
todos os cursos, possa
avançar nos conhecimentos
sobre a criança concreta e as
formas que ela tem de se
relacionar com o mundo,
especialmente através das
brincadeiras, dos jogos e das
interações sociais, elementos
estes centrais para a
construção de um projeto
pedagógico voltado à
educação infantil. (KIEHN,
2007, P. 102).

Desse modo, o professor que vai atuar com a criança pequena deve saber que ela mesma é um ser social que possui cultura e história, tendo também direito de viver a infância adquirindo conhecimentos ao longo de seu desenvolvimento. Assim o papel do educador infantil, nesse processo, consiste em contribuir para as formas de compreensão do mundo pela criança e não em sistematização dos conteúdos, haja vista que na Educação Infantil as ações precisam estar centradas na criança. Dessa maneira, "uma das preocupações persistentes da Pedagogia nesse sentido pauta-se na valorização das especificidades da criança e 
no reconhecimento da diversidade $\mathrm{da}$ infância nos diferentes contextos socioculturais". (KIEHN, 2007, p. 41).

Portanto, a infância é algo que deve ser valorizado na Educação Infantil. Então cabe ao professor reconhecer a importância dela na vida da criança para que contribua para o seu desenvolvimento pessoal e social, complementando a ação da família e da comunidade, conforme os pressupostos do art. 29 da LDB, já mencionado neste texto anteriormente.

\section{CONSIDERAÇÕES FINAIS}

Acreditamos que os instrumentos tanto de coleta quanto de análise de dados, nos forneceram informações suficientes para compreensão do objeto de estudo ora apresentado.

Sendo assim, os dados presentes nesse artigo evidenciam o quanto a formação de professores para atuação no espaço da creche é, ainda hoje, uma problemática no cenário brasileiro. No decorrer da discussão, em concordância com algumas pesquisas e estudos dessa área, retratamos o quanto o professor de Educação Infantil necessita de uma formação sólida, fundamentada no conceito de criança como um ser histórico e social, bem como na compreensão da infância e das especificidades do trabalho pedagógico de 0 a 3 anos.
Dessa forma, é possível afirmarmos, a partir do olhar crítico para a grade curricular do curso de Pedagogia ora analisado que, de fato a Educação Infantil, principalmente, a creche é quase inexistente nas discussões de disciplinas específicas durante os quatro anos da licenciatura. Esse dado se deve ao fato de que a maioria das disciplinas que envolvem essa temática, são ofertadas como disciplinas optativas e não obrigatórias.

Nossa experiência, enquanto acadêmica e professor formador do curso aqui analisado, nos permite afirmar, com toda a certeza, que até mesmo dentro das disciplinas obrigatórias que visam contribuir para o instrumental básico de atuação com crianças em idade de 0 a 5 anos, a creche é deixada para segundo plano as discussões sobre pré-escola são sempre mais evidentes durante as aulas. Esses dados indicam duas possíveis indicações de encaminhamento para o problema da pesquisa aqui apresentado, sendo eles: 1ㅇ) faz-se necessária uma revisão da grade curricular com vistas à inclusão de mais disciplinas específicas da área como obrigatórias e não optativas e também; 2ํ) a construção de um movimento por uma Pedagogia da infância, isto é, um curso específico para a formação de professores de Educação Infantil.

Nesse contexto, sabemos que são inúmeros os desafios postos à formação inicial dos professores para a Educação 
Infantil. O período destinado a essa formação não tem sido aproveitado, de modo geral, conforme "denunciam" os estudos que dialogamos neste texto, de forma suficiente para que o professor tenha, minimamente, o referencial teórico e metodológico para atuação com a criança pequena, pois todos os conteúdos apresentados nas disciplinas da grade curricular são de suma importância para a formação geral do pedagogo. Contudo, chamamos a atenção para o fato de que os cursos de Pedagogia têm sido realizados de maneira "aligeirada" (TEDESCO, 1998) e, com isso, acabam não tendo tempo suficiente para abordar, em nível mais concreto, os conhecimentos e práticas que se propõe a ensinar.

Contudo, como nos relata Kramer (2003), estamos com a Educação Infantil em nossas mãos, então, cabe a nós, profissionais dessa etapa da educação, continuarmos na luta, dia a dia, no contexto de nossas salas de aulas e, para isso, a formação contínua, permanente, é um pressuposto básico para que a educação e o cuidado, possam acontecer na Educação Infantil, e especificamente na creche, de uma maneira que se tenha uma qualidade de aprendizagem e desenvolvimento.

\section{AGRADECIMENTOS}

Agradeço em primeiro lugar a Deus por esse trabalho, vai os meus agradecimentos ao meu mestre que tem me orientado em todo momento, o professor Klinger Teodoro Ciríaco e meu esposo por todo apoio.

\section{REFERÊNCIAS}

ARAÚJO, B. M. R. A formação dos professores para a educação infantil: novos olhares. Revista de Educação do Cogeime, v. 14, n. 27 dez. 2005.

BOGDAN; BIKLEN. Investigação qualitativa em educação: Uma introdução à teoria e aos métodosPorto, Portugal: , Ed. Porto, 2004.

BRASIL. Ministério da Educação e do Desporto. Secretaria de Educação Fundamental. Referencial Curricular Nacional Para a Educação Infantil. - Brasília: MEC/SEF, 1998.

BRASIL. Ministerio da Educação. LDB. Lei de Diretrizes e Bases da Educação Nacional. 5.ed. Brasília: Biblioteca Digital da Câmara dos Deputados, 2010. Disponível em: <http://www.ufal.edu.br/unidadeacademica/ igdema/ institucional/documentos/ldb-leide-diretrizes-e-bases-da-educacaonacional/>. Acesso em: 20 nov. 2014.

CERISARA, B. C. Por uma Pedagogia da Educação Infantil: Desafios e Perspectivas para as Professoras. In: Caderno Temático de Formação II - Educação Infantil Construindo a Pedagogia da Infância no Município de São Paulo. Janeiro de 2004.

CERISARA, A. B. O referencial curricular nacional para a educação infantil no contexto das reformas. Educação \& Sociedade, Campinas, v. 23, n.80, set. 2002. Disponível em:

<http://www.scielo.br/scielo.php?script=sci_ arttext\&pid=S01013302002008000016\&lng=pt\&nrm=iso $>$. Acesso em: 12 jun. 2014. 
CERISARA, A. B. Professores da Educação Infantil: entre o feminino e o profissional. 2. ed. São Paulo:, Cortez 2002.

KIEHN, A. K. H. A Educação Infantil nos Currículos de Formação de Professoras no Brasil. 2007. Dissertação (Mestrado em Educação) - Universidade Federal de Santa Catarina, Programa de Pós- Graduação em Educação, Florianópolis, SC.

KRAMER, S. Com a pré-escola nas mãos. 14. ed. São Paulo: Ática, 2003.

KRAMER, S. Educação infantil e Formação, a titulação de conclusão: Formação de professores, a necessária democratização da educação infantil. In: KRAMER. S (org.). Profissionais de Educação Infantil: Gestão e Formação. São Paulo: Ática, 2005.

MICARELLO. S. L. A. H.; DRAGO, R. Práticas e Formação: problemas e dilemas. In: KRAMER, $S$ (org.). Profissionais de Educação Infantil: Gestão e formação. São Paulo: Editora Ática, 2005.

KSHIMOTO, M. T. Pedagogia e a formação de professores(as) de Educação Infantil. ProPosições, v. 16, n. 3 (48), set./dez. 2005.

LUDKE, M.; ANDRÉ, M. E. D. A. Pesquisa em educação: abordagens qualitativas. São Paulo: E.P.U, 1995.

SANTOS, O. M. C.; HADDAD, L. As Especificidades da Profissão das Professoras de Creche. EPEAL, 2011.

SANTOS, A. N. A.; LEITE, S. R. M. Formação e prática do professor na educação infantil. 2012. Disponível em: <http://www.uel.br/eventos/semanadaeduc acao/pages/arquivos/anais/2012/anais/educ acaoinfantil/formacaoepratica.pdf santos/>. Acesso em:27 nov. 2013.
TEDESCO, J. C. 0 novo pacto educativo: educação, competitividade e cidadania na sociedade moderna. São Paulo: Ática, 1998.

UNIVERSIDADE FEDERAL DE MATO GROSSO DO SUL. UFMS, Projeto Político Pedagógico do Curso De Pedagogia. Naviraís UFMS, 2011. Boletim Informativo: 2011.

Recebido para publicação em 26/01/2015 Revisado em 02/07/2015

Aceito em 01/10/2015 